\title{
Organizational issues that impact on non-use of equipment for individual protection: a view of ergonomics
}

\author{
Eva Bessa Soares \\ Department of Production engineering - UFOP-Federal University of Ouro Preto, 115 Street 36, District: Loanda, \\ João Monlevade/MG. 35931-008. Brazil.
}

\begin{abstract}
The investigative focus of this paper is the issue of non-use of PPE (personal protective equipment) in a trading company of chilled and frozen food products. To conduct the study we have used an ergonomic work analysis that allowed us to highlight important organizational aspects that contribute to the non-use of such equipment. In conclusion, there are suggestions for minimizing problems.
\end{abstract}

Keywords: ergonomics, occupational exposure to cold

\section{Introduction}

Occupational exposure to cold is a challenge to workers and also to specialists in job safety. The work activities that require exposure to cold can be divided into two groups: outdoor activities (civil construction, agriculture, fishing and others) and work carried out in closed environments (cold storage chambers, ice making, ice cream, slaughter and deboning of animal carcasses, jobs on trucks carrying perishable items and others).

To workers, activities in cold environments constitute a considerable risk to their health and can cause damage ranging from simple discomfort, illnesses, work-related accidents to even death as in cases where the worker is accidentally confined for long periods of time in a chamber with a very low temperature.

For professionals who work with job safety, the challenge is to evaluate the unsanitary conditions and provide PPE (personal protective equipment) that reduce the discomfort caused by the cold and offer the best possible conditions to carry out the work. The protection from cold exposure must not allow the core body temperature to fall below $36^{\circ} \mathrm{C}$, so the measures which may be taken are as follows: adopting the cap for head protection gear, rubber boots for the feet, gloves for the hands, thermal jackets for the torso and thermal pants for the legs or even thermal jumpsuits to protect the entire body.

It is the responsibility of the job safety professionals to abide by the laws regulating work in cold environments so that the correct protective measures are taken. One aspect that must be considered is that prescribed in Article 253 of the Labor Code, or "C.L.T." (Consolidation of Labor Laws), and the recommendations of the ACGIH (American Conference of Governmental Industrial Hygienists) that merit consideration, as the parameters reported in relation to one's limits of tolerance to occupational cold are to be adopted. Among which may be cited: a) when the temperature falls below $16^{\circ} \mathrm{C}$ and the activities are sedentary, gloves must be worn; b) continued exposure of any part of the worker's skin to a temperature of - $32^{\circ} \mathrm{C}$ is strictly forbidden; c) prevention so that no worker remains alone in a cold environment. To keep watch over this individual or work in pairs; d) for work in wet environments, the garment should be water repellent; e) do not require of newly-hired professionals full-time work in cold environments. The introduction to work in cold environments should be done gradually so the worker can adapt to the working conditions and garments; $f$ ) the operators must be trained in the safety procedures, before being assigned to workstations. 
Ergonomics is a science that studies the interactions between humans and their work and all the elements which compose it: tools, environmental conditions, relationships between people, among others. There are many concepts of ergonomics, however it may have been best described by the International Ergonomics Association (IEA) and is today known worldwide. "Ergonomics (or Human Factors) is a scientific discipline related to understanding the interactions between human beings and other elements or systems, and the application of theories, principles, data and methods to projects with the aim of optimizing human well-being and overall system performance" [1].

Job safety "is the prevention of losses" [9]. This process is accomplished through technical or human actions which are characterized by preventive means. One of the concerns of professionals who work with job safety is to provide, guide and observe the correct use of PPE (personal protective equipment). Accident prevention is the objective they want to attain. This safety is characterized as a set of measures adopted to minimize workplace accidents, occupational diseases, while also preserving the integrity and ability to work for professionals involved in the working conditions [7].

The field of study and action of ergonomics relates to the field of occupational safety in that both disciplines are concerned with the welfare of the person while carrying out their functions.

The ergonomic demand present in the context of this paper consists of identifying, in the production routine of a company that markets frozen and refrigerated food products, some factors hampering the use of PPE (personal protective equipment) by employees who work in the cold sector.

At the request of company management, this study focused more on questions regarding the use of jackets and pants, to protect against thermal agents, however other protective equipment is also necessary in the job routine of the company's employees, as is the case of rubber boots and thermal gloves.

\section{A brief theoretical review of personal protective equipment and its use}

According to NR 06 (Brazilian regulatory norm of the Ministry of Labor and Employment), personal protective equipment (PPE) is any means or device for personal use intended to preserve the physical integrity of the employee in the exercise of their functions. Use of this equipment in isolation does not prevent the accident itself, but can protect the user when the risk is linked to his role/position. Thus, its use should be linked to a set of measures to promote the safety and health of the workers.

Use of this equipment is provided for in the Brazilian labor legislation, and the CLT (Consolidation of Labor Laws) addresses the company's obligation to supply them to their employees, without charge, and that they be riskappropriate and in perfect working condition. If the company does not supply them and accidents occur, this company will be liable under the law. In NR6 (Brazilian regulatory norm of the Ministry of Labor and Employment) the employer's obligations are reported in relation to the supply of the equipment for individual protection, the employees being responsible for its use, storage and safekeeping.

The PPE (personal protective equipment) is divided into categories according to its use. There is equipment for head protection: helmets; for hearing protection: ear muffs and ear plugs in a variety of models; torso protection: aprons, thermal jackets; hand protection: gloves in leather, plastic, rubber, anti-cut, in the case of artificially cooled environments thermal gloves must be provided; foot protection: boots (thermal, steel-toed, with high and low shafts, etc.); eye protection: goggles; face protection: mask, along with many others that should be used in specific situations.

In the literature on job safety, we find a wealth of material on the question of the company's obligation in safety management. The idea, which has been widely emphasized, can be summarized in the following way: it is not enough for the company to supply the PPE (personal protective equipment); it must enforce its use and punish those workers who insist on not using it. The CLT (Consolidation of Labor Laws) in Article 158 characterizes as a wrongful act any instance where the employee unreasonably refuses to use the protective equipment provided by the company. Unfortunately there are few publications that have portrayed the real motives that lead workers 
to non-use of such equipment, especially in artificially cooled environments, such as the research in question. Herein lies a criticism in relation to the effectiveness of enforcement and punishment by the company towards workers about their nonuse of such equipment. This article defends the idea that the job safety management requires a set of educational actions that must be continuously developed involving all the professionals of the company.

The first studies on the issue of PPE acceptance (personal protective equipment) were carried out in mines and steel mills in the years between 1961 and 1964. These studies were conducted by the European Coal and Steel Community (ECSC) and sought results which can be used in actions to help prevent accidents.

Currently there is material in widely-circulated newspapers in Brazil and specific sites about job safety that address the subject very superficially and attribute the issue of non-use of PPE (personal protective equipment) to distraction, negligence etc., but unfortunately do not deepen their analysis of this issue which is much more serious and must be scientifically analyzed.

When conducting research at 17 companies in the construction industry in Brazil in 1997, [5] it concluded that the failure to use personal protective equipment is not the exclusive fault of the workers, since companies that carry the responsibility and obligation to provide them do not always honor them. One issue of concern found on the job is that many company directors do not in fact know which PPE (personal protective equipment) are necessary to protect their workers in civil construction and some do not even know they are required. The results show, for example, that $70.6 \%$ of companies do not provide protective equipment for the torso of their employees. The author points out the need to refit some protective equipment to the physical shape of the Brazilian workers, much of which is copied from American standards. This aspect explains that on account of the equipment being uncomfortable, many workers dispense of them during the workday.

Regarding the previous question, there is the study by [8] dealing with the use of PPE (personal protective equipment) by the civil construction workers. We have discovered that many workers do not use the equipment alleging discomfort. Their findings showed that the higher the level of education of the workers, the greater the aware- ness that they have regarding the need to use such equipment and also that non-use increases the severity of work-related accidents in this sector.

Performing work activities in low-temperature environments without proper protection can be harmful to health (e.g. wounds, skin cracks and necrosis in the skin, aggravation of rheumatic diseases, predisposition to respiratory diseases, etc.).

Work under these conditions requires more muscular effort, requiring more the hands, arms and neck. The low temperature of the extremities causes a reduction in strength and neuromuscular control increasing the likelihood of accidents and mistakes. For this reason protective equipment is necessary to mitigate these factors [1].

\section{Methodological approach}

In this study we used the EWA (Ergonomic Work Analysis) and it was taken as the basis for the methodological model proposed by [6]. The ergonomic work analysis consists of analyzing the work in the context where it is carried out to understand the mechanisms used by the worker to reach the goals set by the company. After this analysis, it seeks to develop hypotheses and transform the situations at work in order to provide health, safety and comfort to the workers, and increased productivity for the company.

This methodological approach was chosen for being consistent with the object of study of this research (i.e. identifying aspects that hinder the use of equipment for personal protection). Its relevance is justified because the EWA (Ergonomic Work Analysis) can adapt its methods to the work situations under study, analyzing real work situations and understanding the behavior of the workers during the execution of their tasks, identifying the actual requirements of the tasks, the strategies developed, etc.

The study was conducted within fifteen days, including three hours per day of observation, photographic documentation and collection of utterances totaling 45 hours of field work. Moments of high demand for production and sales (morning and afternoon) that are characterized by increased customer traffic in the store and higher number of employees working in the sector, allowing to better understand the sector dynamics. 


\section{Case study}

\subsection{General characteristics of the company studied}

It is a supermarket chain with nine years' experience in the market, with five stores in the metropolitan region of Belo Horizonte (in the state of Minas Gerais in Brazil), and at this stage its staff consists of roughly one hundred and sixty employees.

The store under study is the largest of the chain in sales and in number of employees (56 professionals). It is located in a neighborhood in the north of the city, on a busy road that connects the downtown to several neighborhoods. This store, for its location, serves customers of all socio-economic classes: A, B and C. Its hours of operation are Monday through Friday from 7 am to midnight; on Saturdays and Sundays, it operates from 7 am to $10 \mathrm{pm}$. The work shifts for employees from the sector in this study called "Cold Product Sector" is: from 6 am to $3 \mathrm{pm}$; from 10 am to $6 \mathrm{pm}$, and from $4 \mathrm{pm}$ to midnight.

According to the supervisor, the size of the team is determined according to the needs of the sector originating from the demand of customers in the store. In the morning, there is a greater number of employees than during the afternoon or at night. Those with greater experience work in the morning, since this team must develop a plan for sales during the afternoon and night shifts, aside from working to organize the store.

\subsection{Sector characteristics of cold products and production}

From the observations, we were able to conclude that there is greater customer traffic early in the morning (from 7 am to $9 \mathrm{am}$ ) and in the late afternoon (from $5 \mathrm{pm}$ to $8 \mathrm{pm}$ ). The production in the cold product sector is intense during these times, and more relaxed during others.

The unloading of goods in the store takes place every day starting at $7 \mathrm{am}$, but from the cold products sector only in the morning (from 7 am to 12 noon) to ensure a constant adequate temperature in the trucks and prevent product decay on arrival.

The cold products sector is responsible for unloading the products that arrive on trucks from suppliers or from the company's very own product center, repackage them in the frozen food and refrigerated food chambers, prepare and display in the sales area of the hall (store) the cold products (ham, mozzarella, cheese, lingüiça, sausages, etc.) or simply display those products which need no prior preparation like milk, yogurt and others. In this sector, preparing means: slicing products, packaging, putting price tags and labels to identify the supplier of the product.

This sector is located in the back of the store near the drop-off point for merchandise and attached to the delicatessen. It consists of two refrigerated rooms for the preparation of refrigated products and also 03 (three) chambers: one for packaging frozen food products and two for refrigerated food products.

\subsection{Working population}

The staff of the sector under study consists of 14 personnel, 04 females and 10 males. One is an undergraduate, three have high school degrees and the rest have completed primary school. All are in their first job. The age of the team ranges from 22 to 33 years. The time spent with the company ranges from seven months to two years.

\subsection{Distribution of Tasks}

The supervisor reported that all employees are familiar with the routine, however realized that each of them produce better results in a given task. So, he takes advantage of the abilities of each one. Examples: a) if an employee does not have the patience to deal with the public, the supervisor will send them to slice food products; $b$ ) an employee who is more careful about hygiene and organization is assigned to work at the sausage counter, serving the public and c) an employee who can not carry any weight is assigned to organize the display counters.

The tasks are distributed as follows: the team that unloads the goods from the trucks must store them in the appropriate chambers; one team is assigned exclusively to serve customers at the counter; the team that prepares the products (slices, packs and places the labels) is responsible for the display and replacement of the trays at the counters. The sanitization of the chambers should be performed once a month according to the employee schedule while the preparation rooms shall 
be sanitized at least twice a day by the least occupied team.

\subsection{Production flow in the cold products sector}

After the open observations that allowed for a general idea of the sector's operations, we selected the following steps within the flow of production: a) unloading of goods packing them in the chambers; b) organization of the chambers and c) preparation of products for display (this production step involves entering the chamber, slicing using an electrical device called a slicer, packaging using seal equipment and placing the price tags).

The choice of these steps is justified because they require entering the chambers, at which point the operators need to use all PPE (personal protective equipment) and the object of study was to better understand the aspects hindering their use.

The unloading should occur in the morning, between 7 o'clock and 12 o'clock, upon delivery of products from suppliers (cheese, yogurt, etc.) that are also organized in the chambers by the staff from the cold products sector and also in the afternoon, betweem $6 \mathrm{pm}$ and $7 \mathrm{pm}$, with the arrival of frozen and refrigerated food products on trucks coming from the company's cold products center. At the same time, the promoters (employees of these companies) enter the chambers to remove products that have been stored, to place them on display. Meanwhile, new products are being stored in the place of those destined for the sales area.

These times have been established because the products involved are perishable. Although the trucks have a refrigeration system, the process of unloading them under the hot sun can make them unfit for human consumption and cause losses for the company.

There are products that need to be prepared (sliced, packaged, with price tags attached) before going on display. The promoters and store employees enter the chambers to remove them, then go to the preparation room, after preparing them, send them to the display area.

\subsection{Comparison of assigned work to actual work}

The assigned work consists of: a) unloading of the goods of the cold products sector that arrive on trucks, from the company's own cold product Center or from suppliers;

b) arrange them in the chambers of the frozen and refrigerated food products according to the characteristics of such goods;

c) organize them into islands of frozen foods, counters or upright freezers in the store's sales area keeping in mind the expiration date, presentation, display form, verifying if they are priced, if the price tags are in the correct place, easily visible to customers;

d) slicing, packaging, and putting price tags and labels to identify the name of the product supplier;

e) observing the need for display of sliced products, supplying them where appropriate;

f) serving customers at the sausage counter (weighing according to customer request and putting the label on the package indicating the price);

g) sanitizing the workplace: chambers and preparation rooms.

Below is an example of the aforementioned routine of production assistants of the cold products sector to illustrate some of the characteristics of the actual work of these professionals:

a) Employees unloading goods: trucks do not always meet the set times (early morning and late afternoon). Problems may occur in transit or there may delivery delays at other stores or other companies (suppliers' trucks pass by many supermarkets). Sometimes they arrive at noon. A time like this part of the cold products sector staff is having lunch, the sun is very intense and the traffic on the avenue, where the store in question is located, is very congested. All these factors create an extra burden for the production assistants who will perform the unloading of the goods. They carry out this work under a great deal of time pressure, as there is a risk that the truck will be fined or even be towed due to an inappropriate unloading time. The personnel will unload the products using carts, forklifts or even by carring boxes of products on their shoulders. These goods are stored temporarily in store aisles that allow access to the chambers. After finishing the unloading, they try to organize the products in the chambers. It was discovered that the chambers are too small to meet the store's sales' demand. The employees store the products haphazardly onto the shelves, supporting the boxes on wooden crates on the 
floor inside the chambers, piling them on top of each other, in the spaces where they fit.

With the products poorly kept and packed, some boxes fall apart due to moisture and the weight of the products packed on top of them. The production assistants have one extra task which is to ensure that the products do not fall from the boxes and scatter on the ground contaminating the chamber, as they are food products. If this should occur, they should be discarded in the trash, thus representing a loss for the company. Unloading is a task that requires frequent movement of personnel moving in and out of the store and the chambers. During this stage, we discovered that no employee is seen using the protective equipment for protection against thermal agents (jacket, pants and thermal gloves). There is a transition between exposure to heat (under the hot sun) to the cold inside the chambers.

The following are extracts from recorded utterances and interviews collected from the production assistants during the work routine. These issues relate to the use and non-use of protective equipment.

Figure 1

Synthesis of situations collected from observations of the job routine of the production assistants in the cold products sector. Source: prepared by the researcher.

\begin{tabular}{|l|l|}
\hline \multicolumn{1}{|c|}{ Situations perceived } & \multicolumn{1}{|c|}{ Operators' Utterances } \\
\hline $\begin{array}{l}\text { A worker replacing goods in } \\
\text { a display island of frozen } \\
\text { products in the store. }\end{array}$ & $\begin{array}{l}\text { "I feel very cold. I still ha- } \\
\text { ture of the sector." (SIC). } \\
\text { The supervisor explained that } \\
\text { the employee is new, being the } \\
\text { only one he allows to perform } \\
\text { this work wearing a jacket to } \\
\text { prevent him from getting cold. }\end{array}$ \\
\hline $\begin{array}{l}\text { A worker replacing frozen } \\
\text { food products for a period of } \\
\text { 1h 45m (one hour and Forty- } \\
\text { five minutes) without gloves, } \\
\text { presents his dark hands due } \\
\text { to diminished blood circula- } \\
\text { tion. }\end{array}$ & $\begin{array}{l}\text { Ithink it would bes. But, in this store there } \\
\text { aren't any gloves." (SIC). }\end{array}$ \\
\hline $\begin{array}{l}\text { A worker replacing goods in } \\
\text { the store's upright freezer } \\
\text { wearing a thermal jacket. }\end{array}$ & $\begin{array}{l}\text { "I get very cold here, that's } \\
\text { why I wear this jacket". (SIC). }\end{array}$ \\
\hline $\begin{array}{l}\text { Two workers working in the } \\
\text { aisle organizing boxes for a a } \\
\text { period of 40' (forty minutes) } \\
\text { wearing jackets. }\end{array}$ & $\begin{array}{l}\text { One states: 'I've already } \\
\text { gotten used to wearing it. } \\
\text { whole day. I even eat lunch } \\
\text { with it on". (SIC) } \\
\text { The other: "I put on this jacket } \\
\text { so I wouldn't get my clothes }\end{array}$ \\
\hline
\end{tabular}

\begin{tabular}{|c|c|}
\hline & $\begin{array}{l}\text { dirty. Look at how filthy these } \\
\text { boxes are”. (SIC) }\end{array}$ \\
\hline $\begin{array}{l}\text { An operator organizing } \\
\text { products inside the refrige- } \\
\text { rated food chamber set at } \\
10^{\circ} \mathrm{C} \text { for one hour }\end{array}$ & $\begin{array}{l}\text { "These jackets are always } \\
\text { dirty. The butchers use them a } \\
\text { lot and they let the meat touch } \\
\text { the jacket. I can't stand using } \\
\text { them. Sometimes they are sent } \\
\text { to be cleaned, but they don't } \\
\text { stay clean for long". (SIC). }\end{array}$ \\
\hline $\begin{array}{l}\text { An operator washing the } \\
\text { floor inside the refrigerated } \\
\text { chamber. The temperature at } \\
10^{\circ} \mathrm{C} \text { (ten degrees). }\end{array}$ & $\begin{array}{l}\text { "I never wear that jacket. I'm } \\
\text { not cold. Look at how dirty it } \\
\text { is." (SIC). }\end{array}$ \\
\hline $\begin{array}{l}\text { A worker enters the refrige- } \\
\text { rated chamber set at } 10^{\circ} \mathrm{C} \\
\text { (ten), remains inside for a } \\
\text { period of } 15 \text { seconds, leaves } \\
\text { with two pieces of mozzarel- } \\
\text { la to be sliced in the prepara- } \\
\text { tion room (with a tempera- } \\
\text { ture of } 16^{\circ} \mathrm{C}-\text { sixteen de- } \\
\text { grees). }\end{array}$ & $\begin{array}{l}\text { "I quickly ran in and out. I } \\
\text { always grab an extra piece so } \\
\text { I don't have to go in so often." } \\
\text { (SIC). }\end{array}$ \\
\hline
\end{tabular}

These reported incidents are rich in information about the issue under evaluation: non-use of personal protective equipment (thermal jackets and pants). From these observations, we can understand that there are factors hampering the use of the forementioned equipment such as:

a) Lack of training (there is a lack of knowledge regarding the equipment's purpose. One worker wears the jacket to avoid getting his clothes dirty, even though effective protectiagainst thermal agents (cold) at work can only be ensured through routine use of the jacket.

b) Only one thermal glove was available for a 14-member crew handling frozen and refrigerated products during their entire shift.

c) Lack of follow-ups to promote awareness and clarify any doubts regarding use of these equipment.

d) Worker using the jacket throughout the workday. 


\section{Critical evaluation and conclusion}

According to the company's work safety regulations, every time someone walks into one of the chambers, either for the refrigerated or frozen products, they are required to wear all protective equipment against thermal agents (rubber boots, thermal gloves and pants).

Written safety instructions are posted on all chamber doors and next to them at least two jackets and pants are hanging. Only one worker carries a thermal glove. When asked about the glove, some workers replied that they never received it, others claimed to have no knowledge of its existence.

By observing the work routine in cold environments, it was apparent that the workers do not wear gloves, jackets or thermal pants to enter either the refrigerated or frozen chambers, and depending on the time they remain inside, some opt to wear just the jacket. They normally do not wear a jacket if they are just walking in to grab an item. The pants are available, hanging at the chamber entrances, but no worker was seen wearing them. This equipment is barely acknowledged by anyone. Although the supervisor reports that he instructs his workers on the proper use of PPE (Personal protective equipment), it was not confirmed that he actually verbalized the instructions.

The results collected from this on-site survey demonstrate that there is much to be done in the manufacturing process of the company evaluated, so it can fulfill the minimal legal requirements of the Work Safety Legislation, as well as the recommendations of the ACGIH (American Conference of Governmental Industrial Hygienists).

It led to the conclusion that employees are not solely responsible for the problems found when carrying out the recommendation issued by the work safety team, but important organizational issues remain, which require optimization in order to be fulfilled. Among these questions, the issues of methodology and frequency of training sessions by the work safety team should be reviewed. Such activities should possibly be intensified in order to create awareness about the importance of the proper use of health safety equip- ment, besides fulfilling the pertinent legal issues. In summary, these training sessions should not be repetitive activities, but should seek behavioral changes and raise awareness about safe behavior in the work environment. It is a continuous effort to educate and not punish the employees in relation to this issue.

Accidents will not necessarily be prevented simply by making the personal safety equipment available or requiring its use. An investment should be made to create an efficient safety system, which not only fulfills the legal requirements, but also establishes a conducive environment for awareness and responsibility towards employee safety, increased productivity and also, reduced losses for the company.

\section{References}

[1] J. I. Abrahão [et al.] Introduction to Ergonomics: From Practice to Theory. São Paulo: Blucher, 2009.

[2] ACGIH - American Conference of Governmental Industrial Hygienists. Translation ABHO, Limits of Exposure to Chemical Substances, Physical Agentes and Biological Indices, p.155-163, Cincinnati, OH, 1999.

[3] BRAZIL LABOR MINISTRY. Regulatory Standard 17 ( NR-17) and Regulatory Standard 06 (NR-06).

[4] EUROPEAN COAL AND STEEL COMMUNITY (ECSC). Available at: www.sosa.pt/pub/doc/coloquio_spsho_06.pdf. Accessed 4/20/2011.

[5] M. Z. Grohmann, Work Safety Through PPE Use: In: Annals of the XVII National Conference of Industrial Engineering, Gramado, 1997.

[6] Guérin, et. al. Understanding the Work in order to Transform It. The Practice of Ergonomics Translation: Giliane M. J. Ingratta and Marcos Maffei, São Paulo: Edgar Blucher LTD., 2001.

[7] C. Marangon, Job Safety and Ergonomics. Available at: http://www.areaseg.com. Accessed 11/10/2010.

[8] G. M. P. Potkova. Evaluation of Factors Involved in the Use of PPE by Civil Construction Workers: the Case of the Itaipu Binational. Falls Dynamic College. Monograph. Civil Engineering Department. Foz do Iguaçu. Paraná, 2007.

[9] S. I. Vieira. Handbook on Health and Job Safety: Safety, Hygiene and Occupational Medicine. São Paulo: LTR, 2005. 